\title{
Article
}

\section{What makes young people tick? A qualitative analysis of the beliefs and perceptions of school aged children towards PE and healthy living in 'the sickest area of Europe'}

Cowley, J., Kiely, J., and Collins, D.

Available at http://clok.uclan.ac.uk/18008/

Cowley, J., Kiely, J., ORCID: 0000-0001-9817-0224 and Collins, D. ORCID: 00000002-7601-0454 (2017) What makes young people tick? A qualitative analysis of the beliefs and perceptions of school aged children towards PE and healthy living in 'the sickest area of Europe'. International Journal of Adolescent Medicine and Health . ISSN 0334-0139

It is advisable to refer to the publisher's version if you intend to cite from the work. http://dx.doi.org/10.1515/ijamh-2017-0050

For more information about UCLan's research in this area go to

http://www.uclan.ac.uk/researchgroups/ and search for < name of research Group>.

For information about Research generally at UCLan please go to http://www.uclan.ac.uk/research/

All outputs in CLoK are protected by Intellectual Property Rights law, including Copyright law. Copyright, IPR and Moral Rights for the works on this site are retained by the individual authors and/or other copyright owners. Terms and conditions for use of this material are defined in the policies page. 
What makes young people tick? A qualitative analysis of the beliefs and perceptions of school aged children towards PE and healthy living in 'the sickest area of Europe'.

Joe G Cowley, John Kiely and Dave Collins

Institute of Coaching and Performance, School of Sport and Wellbeing, University of Central Lancashire, United Kingdom

School of Sport and Wellbeing, Greenbank Building, University of Central Lancashire,

PR1 2HE. Email: JCowley@uclan.ac.uk

\section{Short Biography}

Joe Cowley

Joe is currently a Professional Doctorate in Elite Performance candidate at UCLan. He is also a Physical Education teacher at West Lothian Council, is active in teaching community based exercise and physical activity programs and has lectured in both Further Education and Higher Education Joe has presented aspects of his doctoral work at several international and national conferences.

John Kiely

John is a Senior Lecturer at the Institute of Coaching and Performance, UCLan, supervising post-graduates working towards Professional Masters and Doctorates in various dimensions of elite performance. He has previously worked with various World champion athletes in diverse sports and international teams.

Dave Collins

Dave heads the Institute of Coaching and Performance (ICaP) which focuses on a broad spectrum of human challenge. The majority of this work is in high level sport, encompassing 
training and preparation, expertise in coaching and support science disciplines, skill development and refinement, and talent development. He also addresses policy in these areas, together with broader elements of performance and coaching in business, military/emergency services and adventure education.

As an academic, Dave has over 130 peer-review publications and over 40 books and book chapters. To date, he has attracted over $£ 2.5 \mathrm{M}$ in external funding to his various University posts and has served on Government Committees at regional and national level. Dave has supervised over 30 postgraduate research degrees, and currently directs studies for another nine $\mathrm{PhD}$ and 15 Professional Doctoral students. 
What makes young people tick? A qualitative analysis of the beliefs and perceptions of school aged children towards PE and healthy living in 'the sickest area of Europe'

\begin{abstract}
Scottish children are reported to be among the least active in the world, additionally Scotland has previously been labelled 'the sick man of Europe' on account of its poor health record. In response, the Scottish Government has implemented a range of policies with a strong focus on increasing physical activity (PA), Physical Education (PE) and the integration of health and wellbeing (HWB) with the aim of promoting and sustaining PA throughout life. To date, limited qualitative research exploring pupil perspective of PE lessons and HWB exists. To address this deficit, within this study, focus groups were conducted with 39 secondary school pupils (S1-S2). The findings indicated that delivery of traditional PE lessons, prioritizing sporting ability, can act as a participation barrier to pupils who consider themselves 'non-sporty'. Accordingly, a shift towards pedagogical models, rather than simply blocks of sports-related activities should be the priority of educators.
\end{abstract}

Key words: Adolescents, Physical Education, Activity, Health and Wellbeing 


\section{Introduction}

\subsection{The current situation}

Scottish children are reported to be among the least active in the world. An analysis of 38 nations ranked Scotland as joint last for physical activity (PA) and excess screen time activity (1). Furthermore, amongst $11-15$ year olds, only $21 \%$ of boys and $15 \%$ of girls in Scotland met the Scottish, UK, and international standard recommendation of at least 60 minutes of PA of at least moderate intensity per day (1). Scotland has previously labelled 'the sick man of Europe' on account of its poor health record, lifestyle factors and higher mortality rates when compared with other European countries (2). Yet, paradoxically, the recent 'Active Healthy Kids Report' card showed Scotland has one of the best environments and infrastructure for outdoor play in comparison to other nations (1).

Consequently, in the drive to improve the health of the nation, the SNP-led Government has implemented a range of policies with a strong focus on increasing PA, Physical Education (PE) and integration of health and wellbeing (HWB) in schools, with a focus on promoting activity during the first decades of life with the aim of sustaining PA throughout the lifespan.

Scottish education, and more specifically PE, have been the source of great change in the past decade (3). The implementation of Curriculum for Excellence (CfE) in the education system, coupled with the implementation of new national qualifications together with integration of PE into the new HWB framework are examples of this change. The integration of PE into the HWB framework, and indeed the new interdisciplinary status of HWB in the Scottish curriculum, are undoubtedly policy driven reactions to the state of Scottish health and the recommendations emerging from the Scottish physical education review group $(4,5)$. 
Adolescence is a critical time for forging PA habits and promoting lifelong PA participation. The link between school PE and adult health has been well established in the literature (6-9). Additionally, the early years of schooling exert a significant influence on PA patterns, particularly during the early phase of primary school when essential movement skills are installed $(10,11)$. Yet as children leave school there is typically a very high dropout from physical activities and sport, suggesting that current PE teaching methods are not adequately lending themselves to sustainable activities $(11,12)$.

Accordingly the school years appear fundamental to adequately instilling the behaviours and habits crucial to creating healthy lifestyles (11,13-17). Additionally, Cale and Harris (2009) (17) have cautioned that "for PE to act as a vehicle for lifelong activity, the content and delivery of the curriculum is critical and it is important that young people are provided with the knowledge, understanding and skills required for lifelong participation in physical activity and with positive, meaningful and relevant PA experiences that will foster positive attitudes and confidence”.

\subsection{Relationship between health behaviours and Physical Activity}

Engagement in PA, sport and exercise exerts a positive remediating effect on the negative consequences of accumulating life stress. Previously, we postulated that one of the potential underlying causes of the Scottish (and associated Glasgow) effects, was the additive 
combination of lifestyle, cultural and environmental stressors to which many Scots are exposed (18).

The World Health Organization (WHO) highlighted the importance of organized school PA and sport. For example, higher level sports participation has been shown to be associated with other behaviours such as less antisocial behavior , alcohol consumption, use of illicit drugs, and engagement in violent activities (19). Whilst importantly, those who are not engaged in competitive sports should be encouraged to be physically active 'outside of the rubric of competitive sports' (20). The most accessible method of targeting younger people to uptake sport and PA is through the school PE program. Undoubtedly, Physical Educators play a role in not only teaching PE in the curriculum but in promoting health messages so crucial to establishing and sustaining healthy behaviours throughout life.

Despite the curriculum change and an implementation of policies with a strong PA message, and the subsequent increase in school PE, there is little evidence that this has had an impact on young people's PA levels, health and wellbeing understanding and health behaviours. It has been suggested that the recent findings of low PA can be attributed to Scotland having a culture of low PA. Additionally, barriers such as children lacking the freedom to play in order to build confidence, autonomy and resilience has also been cited as a contributing factor (1).

\subsection{Young people's understanding of $\mathrm{PA} / \mathrm{PE}$ and healthy living}

It has been suggested young people have an insufficient, inadequate understanding of healthy behaviours such as PA, PE and other HWB factors (21). By way of example, Keating 
et al., (2009) reported a lack of health-related fitness (HRF) knowledge amongst American Collegestudents. Similarly, Powell and Fitzpatrick (2015) (22) highlighted that when New Zealand primary school children conceptualized their perspectives on fitness and health topics, that the predominant definition of fitness was the avoidance of 'being fat' (22) and, in the UK, Roth and Stamatakis (2010) (23) reported most young people have a poor familiarity with PA guidelines. For females, knowing the guidelines was associated with meeting them, but the relationship between knowledge and application was weak amongst boys(23). More specifically in relation to school PE, previous work suggests that young people are more likely to continue PE participation if they have a teacher that they like, whom they perceive as professional and who offers them a variety of activity choices $(24,25)$.

Whilst confusion may arise as to what constitutes effective PA, PE and/or exercise, evidence demonstrates that, in the domain of healthy eating and diet, that most young people are adequately knowledgeable yet lack the necessary skills to implement healthy eating strategies within daily life (23).

An accurate understanding of attitudes and beliefs is essential in planning effectively targeted remedial strategies. Nevertheless, there is a paucity of qualitative evidence investigating young people's beliefs and perceptions relating to healthy living. Furthermore, the research base pertinent to young people's knowledge and understanding of $\mathrm{HWB}$, fitness and $\mathrm{PE}$ and PA is limited, and especially in relation to the Scottish population (26). Greater insight, within these realms, may greatly assist those tasked with developing pedagogical strategies targeting the development of healthy, active lifestyles. 


\subsection{Aims of the study}

Bearing in mind the stress-inducing cultural aspects of Scottish life and the convergence of multiple other stress-promoting phenomena in Scotland, this paper seeks to qualitatively assess the opinion of 11-13 year old's in the West of Scotland, to better understand these young people's perception of the term healthy living . Accordingly, the aims of this study are:

- To investigate young peoples' perceptions and attitudes to PE at school, and their understanding of PA in their daily lives.

- To explore young peoples' perceptions and attitudes to healthy living, and to inform the design of novel teaching methods that professionals could use to communicate HWB messages to adolescents in order to improve their health behaviours.

\subsection{Methods}

\subsection{Approach}

In order to address the posed research questions, an inductive thematic analysis, using a bottom up approach, was selected (27). A thematic framework was applied to all the data. Inductive thematic analysis does not rely on existing, pre-determined, theoretical perspectives, but instead relies on the data itself: thereby providing dimensions of theoretical flexibility (27) Accordingly, the coding and theme development were directed by the content of the data. This approach is recognised as particularly useful when little is known about the topic under consideration $(27,28)$. Thematic analysis was first recognised as a qualitative method in the 1970's, and there are several methods of application. The protocols of this study follow those outlined by Braun \& Clark, (2006) (27). The analysis procedures are discussed in more detail in section 2.5. 
A topic guide was devised based on a literature review (see Appendix 1). This review examined adolescent's attitudes to health and determines what aspects of healthy living are important to them. The guide consisted of nine open ended questions focusing on the research question: What do young people understand by the term 'healthy living?'

Focus groups should contain 3-4 major questions to allow for the facilitator to fully explore each issue in suffice detail to provide a rich data set (29) The use of group discussions may generate comments that are more critical than those generated in one-to-one interviews (30). The development of focus group questions can be categorised in one of three ways:

1. Highly structured-These do not allow for a great deal of flexibility within the focus group session but are useful in gaining specific data and may be useful in keeping the focus group on topic.

2. Moderately structured-These allow for flexibility where the session builds around a core set of questions.

3. Minimally structured-These are useful in early stage research but require a great deal of facilitator experience due to their reliance on one or two pre-determined questions $(30,31)$.

In order to allow flexibility but keep a structured flow to the focus group session this study took a 'moderately structured' approach. This would allow the facilitator to encourage each participant for a response and allow discussion of these responses, therefore allowing adequate 
data capture, whilst keeping a structure to the session. The interview guide also included a series of prompting statements pertaining to the research questions and relevant prompting examples. The order of the questions was also considered by the researcher to allow the session to flow naturally and therefore stimulate maximum discussion.

\subsection{Ethical Approval and Participant Recruitment}

Advice was sought by the author JC regarding ethical requirements. Ethical approval was granted to administer and carry out the project. Ethics adhered to the following conditions:

Participation will be voluntary, children and parents will be provided with information sheets and asked to sign consent forms.

$>$ The transcripts from face-to-face interviews and focus groups will be irreversibly anonyms so that the participant's identity is fully protected.

It is not possible to identify the individual from any direct quotation used in the reporting of the project.

Roman Catholic schools participating requested that questions pertaining directly to sexual activity, sexual health or contraception should not be asked under the guidelines of the Scottish Catholic Education Service, which 'sets national policy on all educational matters on behalf of the bishops of Scotland.

\subsection{Sampling Strategy}

A purposive sampling strategy was employed in this study. Schools were purposively sampled on the basis of socioeconomic factors and characteristics of the school to provide a diverse sample of participants'. JC contacted secondary schools within the West of Scotland 
category area with the hope of recruiting suitable participants. Further 'lead' assistance was provided by individuals from the Physical Education school liaison coordinators. Researchers visited the schools and gave a presentation entitled "Improving health in young people". This presentation discussed healthy living issues and ask the audience to think about young people's health - what are the challenges and how do we improve things? Following on from this, school children were asked to sign up for focus groups to talk about healthy living and their thoughts about ways to improve health in people like themselves in more detail. In total, three different schools were visited, with a total of ten focus groups being conducted.

\subsection{Procedures}

The focus groups were held in convenient locations for participants. Each group was facilitated by the author (JC), each focus group was 55 minutes in duration. The facilities were visited by the research team one week prior to hosting each focus group to allow familiarisation with the layout and check the venue suitability. On arrival at the venue each participant was welcomed and offered refreshments Informal conversation during this period helped to act as an ice breaker, to create an atmosphere of trust. When all participants were assembled, each participant was given a written consent form long with an oral explanation of the nature of the study. The ethical considerations, option to opt out, confidentiality implications and focus group rules were explained to the participants. All participants received a full explanation of the study and assurances about confidentiality and anonymity.

Each session was digitally recorded using two Olympus voice recorder WS 311M. The discussion was based around the topic guide devised after the extensive literature review as detailed above. Although the session followed a moderately structured questioning process, 
the facilitator intervened to explore and clarify comments made by participants within the group as they arose.

\subsection{Analysis}

The data from the voice recorders was transcribed verbatim by independent transcribers. Express dictate digital software v5.16 was used to listen and re-listen to the anonymous data and compare this to the original transcript to allow a data cleaning process, minimise transcription error and capture any data from participants making comments in the background or by talking over other individuals. Amendments to the transcripts were then verified by a third person independent of the research. Each transcript was analyzed independently by the author using thematic analysis following a six step process and following guidelines as described elsewhere $(27,32)$ (See Appendix 2). Thematic analysis was chosen using a bottom up, inductive approach due to its ability to produce a 'thick description' of the data set, whilst being easy and quick to apply to a large data set $(27,33)$. Emerging themes were identified, these themes were read and re-read until a general consensus was reached. Particular attention was devoted to obviating the risk of quotes being taken out of context or becoming distorted (32).

This process was conducted in order to ensure robust descriptive validity (33).

\subsection{Results}

\subsection{Demographics and summary of themes}

The present study's sample consisted of thirty-nine participants, composed of twenty-two females and seventeen males. The mean age of the participants was $12.56( \pm 0.56)$ years old. It was the intention of the author to recruit 11-13 year olds but the majority of participants were aged 12 years. Participant characteristics are described in Table 1 in the appendix 
Participants were recruited from three schools in Scotland.

School 1, a faith school was positioned fourth in the regional school league tables for 20092010. Twelve percent of the school's pupils are eligible for free school meals. In 2009-2010, fifteen percent of S5/S6 pupils achieved five or more Highers at A-C grade, a figure four percent above the regional average

School 2 . Eighteen percent of the school's pupils are eligible for free school meals, a figure three percent higher than the regional average. In 2009-2010, thirteen percent of S5/S6 pupils achieved five or more Highers at A-C grade, a figure seven percent below the regional average

School 3. This school was positioned twelfth in the regional school tables. Eighteen percent of the school's pupils are eligible for free school meals, a figure three percent higher than the regional average. In 2009-2010, eight percent of S5/S6 pupils achieved five or more Highers at A-C grade, a figure that matched the regional average.

Analysis of the focus groups conducted revealed four main themes:

1. Awareness of current health messages

2. The role of PE and PA in their lives and existing barriers and facilitators to this.

3. The role of image and social acceptance

4. Social influence on health related behaviour and health advice 


\subsection{Awareness of current health messages}

Participants from all schools were highly aware of current initiatives and health messages from the Department of Health and Scottish Government campaigns. Health education messages appear to be getting through to this group to a certain extent. Participants were aware of the constituents of a healthy balanced diet, the importance of PA in maintaining a healthy lifestyle and the causes of diseases such as cancer and heart disease. Furthermore, participants showed awareness of recent campaigns such as those promoting physical activity, as well as those highlighting the negative effects of smoking and excessive alcohol consumption.

"You could walk places instead of taking the car." R5

[Smoking and Drinking] "They lead to heart problems when you are older." R21

The Government campaign for people to eat five portions of fruit and vegetables a day appears to be a health message that the majority of participants are familiar with.

\footnotetext{
"Maybe eat loads of fruit ... not loads of fruit, just eat your five a day and maybe that just the odd time have chocolate or something. " R32
}

"Keeping clean and healthy so when you are older you can get like a good job and education [and eating] your five a day. " R24

When asked, what healthy living meant to them and why it was important, most of the participants' comments were related to illnesses that could occur as a result of an unhealthy 
lifestyle. By far the most mentioned diseases were cancer and heart disease. Some participants raised the issue of longevity.

\footnotetext{
"Maybe later in life so you get more out of your life instead of like having a heart attack younger. " R7
}
"In later life it could leave you susceptible to more diseases and things like that and cancer and things......Heart attacks. " R10

Weight gain, obesity and body image appeared to be important to many of the participants.

Some participants were aware of weight management issues and had basic knowledge of how people may become overweight.
"It all mounts up. Like if you eat a chocolate bar each day then you maybe don't notice it, but like later on you can maybe notice how much weight you've put on from doing it." $R 8$

“Just because you don't want people making fun of you that kind of stuff. If you were a bit bigger so you're always try and keep slimmer, but some people can take that to the limits as well, which isn't great which makes them unhealthier than they may already $b e ” . R 30$

\subsection{The role of physical education and physical activity in their lives and existing barriers and facilitators to this.}


Most importantly, some participants see PE as a vehicle that can help improve quality of life when they are older and help prevent the aforementioned disease.

"PE and taking part in sports clubs is important as it could help prevent stuff like cancer and heart disease when you get old". R34

"Stay fit, stay fit for your life, keep on eating healthy and all that... Like if you're not healthy and fit and you're older then you end up with all those problems with you, if you're fit you've got a better immune system to fight it... [ you can do this by] Being out more, doing PE, exercising and like getting into clubs”. R20

However, the conversation below highlights the importance of image and provided the first clues as to why being socially accepted and conforming to a certain image may act as a barrier (or facilitator) to PE participation.

“...tell me more about why you think that's important, what about taking part in PE for example?" Fac

"Just people, at this age people take a lot of pride in their image usually. Because they go like, at PE and stuff, when it's like free sometimes, the guys like when the girls are in, (they) do like sit ups and press ups and all that.To show off to the girls". R12

Certain aspects of the taught curriculum then further highlight the importance of conformity to a specific image. Similarly, the need for appearing cool was perceived as important in physical education classes amongst male member of all the focus groups: 
“Like people want to be thought as of, kind of [pause] in like the cool group or something like that. Such as fitness test and PE people want to do better to impress... to impress friends". $R 9$

"People get made fun of, like if you get a low score (in fitness testing)". R8

“... all that people get made fun of, like if you get a low...A low score. Then (you get) bullied people are really, really fighting to be the best". R10

One of the strongest subthemes to emerge was the emphasis on competitive sport and sport based drills. This was commented on across gender. Curriculum content was perceived by several people to favour those good at sport or of a competitive nature, as highlighted previously, many participants commented on fitness testing and perceived it to be a negative element of PE.

"I don't like the beep test or having to do press-ups in a minute it's pointless R36".

"Every year it's the same thing when we come back after the summer holidays, ye all line up in the big hall and do the bleep test,then circuits, should be doing fun games like dodgeball n stuff like that. Cos everyone wants to join in then R39”.

\subsection{The role of image and social acceptance}

The image dominant theme and its relationship to social acceptance from peers was not only confined to PE participation but was dominant throughout this study. Most female participants reported that the pop star Cheryl Cole was their ideal role model. Most females 
reported that body image and "being skinny" was important. Although most males did not name specific role models, they did idealise a bulky, muscular physique.

\begin{abstract}
"I think the girl one would be Cheryl Cole. Like I think its most really just [girls] trying to stay skinny, just to be cool and stuff.... [I] think it's more skinny for girls, but it's like bulky [for boys] ... [boys want] more muscle." R11
\end{abstract}

One word which featured a lot throughout each discussion was "cool". This word has connotations of being trendy and being desired. Participants reported that it is crucial for them to be the same as their peers and their main desire appeared to be to 'just fit in'. Popularity is often regarded as the ultimate goal in adolescents' lives and they reported looking up to popular pupils as role models. Some participants reported that younger individuals within the school sometimes take part in unhealthy activities in the hope of being perceived as cool and of being socially accepted. One participant highlighted that peer pressure might influence pupils' decisions to take up smoking, particularly if there is the fear of name calling.

This was highlighted in the following conversation:

"I think it depends what the people like. If I saw someone smoking, I don't think they look cool, but other people might...

... it used to be like people who didn't smoke were the kind of outcasts... the different people, but well now it's kind of if you don't smoke it's kind of different". R10

"What do you mean by that"? Fac.

"Like a lot of people smoke. So it's like peer pressure and everything. So if you don't want to do it, then you could still do it because of the peer pressure". R11

"Yes, because you can be forced into it, that's what. [Usually what the initial stages of it are] ... simple one saying you're like a chicken if you don 't'. R10 
Another participant reported that pupils' fear that they will become victims of bullying and physical violence if they do not take part in smoking and drinking sessions:

[If you didn't take part in smoking and drinking] "Some people would batter you... it happens." R23

\subsection{Social influence on health related behaviour and health advice}

Some participants reported that parental influence was important when it came to making lifestyle decisions, such as whether to choose healthy food or not. It was also discussed that an adolescent would be more likely to smoke or drink alcohol if their parents were smokers or drinkers.

[On seeking health advice and health information] "Hmm, I would probably say my mum [?] because erm she buys like the sweets and she buys the food... [I would say I] want to be a wee bit healthier and she would maybe say yeah instead of going to the chippy or Chinese maybe give you a homemade meal." $R 7$

"Could be because all their family smoke or something so they think that's okay". R19

When asked whom, they would be most likely to go to if they wanted health advice, most participants responded that they would confide in a parent, who would then probably consult their family's General Practitioner. It appears to some extent that gender plays a role in which parent they would turn to for advice. 
"It depends what one [parent]. I mean, for you [pointing to a female member of the focus group]... and she'd probably go with her mother and I'd probably go with my dad". R15

Some participants perceived that some were more capable than others of giving health advice. One participant commented that he would accept advice from his father due to the fact that he was a biology lecturer. He then suggested that if his father did not have a university education, he would be more reluctant to seek advice from him. Surprisingly, many participants did not feel that they would want to share confidential information with their teachers. Participants said they would be more inclined to seek advice from a school teacher whom they felt knew more about the body. PE teachers featured highly on the list of teachers from whom participants would seek advice.

"If your dad was a doctor, maybe you'd [listen to them]... because my friend's mum and dad are both doctors, so you'd probably listen to them...... if your dad was a drycleaner [you wouldn't listen to him].....You don't need to go to college to be a drycleaner. Lawyers need to go to university”. R15

"[I am] probably more inclined to listen to a PE teacher than a French teacher". R14

There were conflicting comments from participants regarding health advice from peers. Some participants commented that they would turn to a friend for advice.

"You'd go to your friend after because friends aren't always going to know everything, but if you wanted you could ask them what they think you should do like." R16 
However, some participants expressed concern that friends might mock them if they confided in them. One participant also commented that the person they sought advice from depended on the nature and confidentiality of advice that he required.

"If it's personal and your family knows about it, like a health issue, then you'd talk to your family and maybe not your friends because your friends might mock you. And you might go to your teachers with a health issue maybe, but I wouldn't go with something personal." R15

\subsection{Discussion}

The use of focus groups allowed a detailed insight into young people's attitudes towards PE, PA and HWB. It was notable that most themes provided a consensus across all the focus groups conducted, though differences in opinions and perceptions will be described when appropriate.

Prior to conducting the research, it was expected that socio-economic factors would be influential in shaping understanding and perception of healthy living (34). This expectation was borne out, as it emerged that pupils from schools in more affluent areas reported less exposure to alcohol, drugs and tobacco. However, awareness of current health campaigns and healthy living issues was consistent across all focus groups.

\subsection{Image, Social Acceptance and Social influence}

The importance of social influence was persistent throughout this study. Similar to previous findings, social influence appeared to influence the thoughts, feelings and behaviour 
of adolescents as they attempted to conform with their peers,(34). The desire to 'fit in' and the need to maintain an image of 'being cool' was influential in determining attitudes and beliefs relevant to participants' perception of PE participation and pertaining to unhealthy activities such as smoking, drug consumption and drinking.

\subsection{PE barriers to participation}

\subsubsection{Fitness testing and competitive activities}

Clearly participation in PE classes, especially when class content was interpreted as 'competitive', was perceived as the domain of the 'cool' sporty group. The use of fitness testing and overly competitive based lessons already favour those who excel at sport, rather than promoting physical activity and education to the diverse spectrum of pupils(17,35). Traditional PE curriculum in the UK usually follows a set structure, beginning with a block of fitness testing and subsequently leading to fitness development lessons, followed by a block of games and aesthetic activities with an emphasis on teacher-directed activities. A similar format follows in a lesson based context where traditionally games lessons are composed of a warm up, skills based drills followed by a competitive game (36).

The data presented within this study highlights that many participants feel that fitness testing and overly competitive lessons presents a barrier to their participation or enjoyment and, potentially, exposes them to an increased risk of bullying. The use of fitness testing in modern PE has previously been severely questioned with doubts raised over the reliability, validity and educational purpose of this (usually compulsory) topic (17). Furthermore, Cale 
and Harris highlighted that the misuse of fitness testing in PE may not only fail to promote healthy lifestyles and PA but could deter young people from participation (17).

The potential for overly competitive games to act as a barrier to participation was particularly evident in games such as football (soccer), where some reported that if they made a mistake during a game then they were 'slagged and bullied' in the changing rooms. Green (2004) argues that there needs to be a move away from competitive, performance oriented sport towards 'the inclusion of more recreational sporting activities', with a more tailored degree of personal choice permitted (37). Additionally, it is apparent that some respondents are aware of weaknesses in the PE curriculum and are aware of some teachers 'churning' out the same thing year after year. This is particularly important when considering that the repetitive aspects of short blocks of activity does little to foster motivation and confidence to promote involvement and lifelong activity $(16,38)$.

\subsubsection{Technology and co-operative learning}

The use of technology and groupwork as mentioned by the respondents in school 3 appears to demonstrate a model based approach to PE teaching namely cooperative learning (36).Co-operative learning involves students being empowered by learning from each other with the teacher acting as a facilitator. The use of a models based approach involves an alternative method of teaching PE and has had success in helping disengaged pupils overcome barriers to participation. The idea that pupils are aware of the repetitive nature of traditional lessons further highlights the point that teacher centred lessons do not lend themselves to an inclusive environment whilst fostering intrinsic motivation. However model based practice such as co-operative learning may offer a means of overcoming the limitations of the traditional approach $(16,36,39)$. 


\subsection{Health behaviour choices}

Whilst this study does not directly evaluate the reasons why adolescents make 'good' or 'bad' choices relating to their health and wellbeing, it is clear that pressure to conform to peer-group norms greatly influences adolescent behaviour. When it comes to choices about smoking, previous work by Michell and Amos identified that peer influence, and the need to appear cool, is more important to females than to males (40). This was partly attributed to boys having other interests, such as sport and computers. However, the findings presented here suggest that the factors influencing decisions on whether to partake in smoking, drinking and recreational drugs are not as gender specific. Boys were as likely as girls to be susceptible to peer influence. The findings do however reiterate the powerful influence male aspirations to conform to ideals of the 'muscular, macho' image of maleness. Females, on the other hand, identified their ideal role model as Cheryl Cole. The desire to imitate and emulate celebrities seems of the utmost importance to many young females and is suggested, by Fraser and Browne (2002), to reflect a deep-seated need to enhance their self-esteem (41) as accordingly, it has previously been suggested that celebrities may be more influential role models to adolescents than their immediate peers (41).

Given that adolescence is recognized as a time when healthy and unhealthy lifestyles are forged, it is important that health and wellbeing messages are appealing to adolescents: hence entailing that health messages should be communicated via a medium relevant to adolescents, and in a language, that appeals to them. Accordingly, the use of peer education from positive role models is one such area that could be developed further, while celebrity 
endorsements may also be influential in communicating positive health and wellbeing messages to adolescents: thereby harnessing adolescents' attempts to identify with their favourite celebrities. Similarly, the use of respected pupils within schools, or the use of young medical students closer to school children's own ages, as demonstrated in previous pilot studies, may prove effective in communicating health messages (42).

\subsection{Peer conformity and bullying}

Paradoxically whilst the 'sporty' avoid being slagged and bullied, as they appear cool, those who partake in unhealthy behaviors such as smoking and drinking were seen as being 'tough' However, for others the fear of being singled out, 'slagged' and bullied was a concern. These participants believed that many younger adolescents succumb to unhealthy activities for fear of being seen as different, whilst some spoke about the threat of verbal abuse and physical violence. The fear of bullying and reports of isolated incidents involving severe peer pressure and bullying corroborates previous research conducted by Michell and Amos (1997), who documented incidences of bullying that could be more appropriately described as physical assault (40).

\subsection{Methodological limitations and strengths}

There are several limitations but also strengths to this study. Firstly, generalizability from focus groups may be limited. Accordingly, the findings of this study may not necessarily extrapolate to the whole Scottish population. Nevertheless, although generalization in focus groups should be treated with caution, tentative inferences may be appropriate where participants share commonalities to comparison populations, such as those from similar backgrounds and socio-economic strata (43). Consequently, suggesting that these study 
findings are likely to be broadly generalisable across similar adolescent populations within Scotland.

Additionally, focus groups and the nature of group interactions may compel participants to concur with opinions they do not necessarily hold. Furthermore, bias due to the presence of socially dominant participants, or an overly dominant moderator, may also compromise validity.

Lastly, the sampling strategies employed in the present study may be vulnerable to bias. Indeed, since the participants were all volunteers, there may be an inherent self-selection bias, whilst the nature of a focus group design involves a relatively small number of participants.

Despite these limitations this study had several strengths. The use of focus groups enables the capture of richly detailed data, while allowing adolescents to articulate their beliefs, concerns and aspirations on health issues (27). The use of a core set of questions within a moderately structured focus group helps eliminate moderator bias, and minimised monopolisation of the discussion' by individual participants (27).

Additionally, the use of a purposive sampling methodology ensured the sample was representative of the requirements of the study: thereby permitting comparisons between opinions of various schools and surrounding areas.

Finally, responses from the initial questions derived from the topic guide suggested that whilst most of the participants were fully aware of health issues and campaigns, a variety of opinions and misconception arose around structured exercise and PA guidelines and practice 
Thereby suggesting that most participants did not have substantial background knowledge of the topics under discussion.

\subsection{Conclusion}

The respondents in this study suggests that the use traditional PE lessons which prioritise those of a high sporting capability, act as a barrier to those seen as 'non-sporty'. The use of technology with the integration of pedagogical models such as cooperative learning should be considered as an exciting, 'novel' way for teaching staff to improve the health attitudes and lifestyles of young people by promoting PE for all, and also increasing awareness of the perils of unhealthy diets and smoking. The findings presented here clearly illustrate that young people are aware of current health messages being delivered both at a national and at a school level. However, whilst getting adolescents to understand important health issues does not present a problem, getting adolescents to practice a positive healthy lifestyle presents a greater challenge. Whilst there does requires a shift in the methods of teaching of PE, the responsibility of health and wellbeing is the remit of all Scottish teachers. However, this too may require alternative approaches. The use of older peer groups and peer coaching in communicating health and wellbeing messages may be one possibility. The present study illustrates the need for a greater understanding of the barriers preventing awareness from becoming action. What has become apparent is that how adolescents 'fit in' with peer groups and how they are perceived by others plays a crucial role in their health choices. Clearly self-identity, social influence and the need to be socially accepted all play important roles in establishing healthy lifestyles in adolescents.

Overcoming many of the barriers normally associated with participating in PE can only be attained if the pupils feel comfortable and supported. Crucially the role of image and 
social acceptance also presents a key barrier in ensuring physical activity and PE participation and adherence in adolescents which is particularly important in ensuring that they remain active throughout life. Further research is required in this field, predominantly to investigate the drop out in PE classes during the transition phase from compulsory PE, especially with regards to the impact of social acceptance and image. Any new initiatives must aim to be socially acceptable to adolescents at school leaving age. Such initiatives should aim to incorporate this medium into their practice rather than having a dismissive attitude towards it. These findings may also be useful in advising stakeholders to develop effective interventions to overcome adherence barriers and suggest that the curriculum is not tailored enough to each individual pupil and may not create the best environment to promote sustainability, additionally, the use of model base practice embracing modern technology should be further embedded into PE classes, which may limit non participation and increase the elements of (44).

Future research should direct school leavers towards physical activities that individuals can sustain throughout life. Whilst the current emphasis in PE is on being active during the lesson, in agreement with Kirk (2013b) (39) the role of PE is not complete until PA is established as a lifelong habit to be adopted even when school is not compulsory, rather than prioritizing short term PA levels.

\subsection{References}

[1] Reilly JJ, Johnstone A, McNeill G, Hughes AR. Results from Scotland's 2016 Report card on physical activity for children and youth. J Phys Activity Health 2016;13:S251-255. 
[2] Bromley C, Shelton N. The Scottish Health Survey UK comparisons a topic report. Edinburgh: Scottish Governement, 2010.

[3] Thorburn M, Horrell A. Power, control and professional influence: the curious case of Physical Education in Scotland. Scottish Educational Review 2011;43:73-85.

[4] Horrell A, Sproule J, Gray S. Health and wellbeing: a policy context for physical education in Scotland. Sport Educ Soc 2012;17:163-80.

[5] The Scottish Executive. The report of the review group on physical education (PERG). Edinburgh: Scottish Executive, 2004.

[6] Fairclough S, Stratton G, Baldwin G. The contribution of Secondary school physical education to lifetime physical activity. Eur Phy Educ Rev 2002;8:69-84.

[7] Shephard R, Trudeau F. Legacy of physical education: long term and short term effects. Ped Exerc Sci 2000;12.

[8] Bélanger M, Sabiston CM, Barnett TA, et al. Number of years of participation in some, but not all, types of physical activity during adolescence predicts level of physical activity in adulthood: Results from a 13-year study.Int J Behav Nutr Phys Act 2015;12:76.

[9] MacNamara Á, Collins D, Giblin S. Just let them play? Deliberate preparation as the most appropriate foundation for lifelong physical activity. Front Psychol 2015;6:1548.

[10] Giblin S, Collins D, Button C. Physical Literacy: Importance, Assessment and Future Directions. Sports Med 2014;44:1177-84.

[11] Jess M, Collins D. Primary physical education in Scotland: the future in the making. Eur J Phy Educ 2003;8:103-18.

[12] Capel S, Whitehead, M. What is physical education? In: Capel S, Whitehead, M, eds Debates in Physical Education. London: Routledge, 2013.

[13] Kirk D. Physical education, youth sport and lifelong participation: the importance of early learning experiences. Eur Phy Educ Rev 2005;11:239-55.

[14] Cale L, Harris J. Exercise and Young People. Issues, implications and initiatives: Basingstoke: Palgrave Macmillan, 2005.

[15] Giblin S, Collins D, MacNamara A, Kiely J. "Deliberate Preparation" as an evidencebased focus for primary physical education. Quest 2014;66:385-95.

[16] Kirk D. What is the future for Physical Education in the twenty-first century? In: Capel S, Whitehead, M, ed. Debates in physical education. London: Routledge, 2013:219-29.

[17] Cale L, Harris J. Fitness testing in physical education - a misdirected effort in promoting healthy lifestyles and physical activity? Phys Educ Sport Pedagogy 2009;14:89108. 
[18] Cowley J, Kiely J, Collins D. Unravelling the Glasgow effect: The relationship between accumulative bio- psychosocial stress, stress reactivity and Scotland's health problems. Prev Med Rep 2016;4:370-5.

[19] Jones-Palm D, Palm J. Physical activity and its impact on health behaviour among youth:Report for World Health Organization. Bulletin Int Council Sport Sci Phys Educ 2004.

[20] Brooks F, Magnusson J. Taking part counts: adolescents' experiences of the transition from inactivity to active participation in school-based physical education. Health Educ Res 2006;21:872-83.

[21] Harris J, Cale L, Duncombe R, Musson H. Young people's knowledge and understanding of health, fitness and physical activity: issues, divides and dilemmas. Sport Educ Soc 2016:1-14.

[22] Powell D, Fitzpatrick K. 'Getting fit basically just means, like, nonfat': children's lessons in fitness and fatness. Sport Educ Soc 2015;20:463-84.

[23] Roberts K, Marvin K. Knowledge and attitudes towards healthy eating and physical activity: what the data tell us. National Obesity Observatory 2011:1-39.

[24] Sandford R, Duncombe R, Morris J, Maddox D. Young people's attitudes towards school and PE in England: Findings from the 'You, School and PE' Survey. 2012.

[25] Linda Rikard G, Banville D. High school student attitudes about physical education. Sport Educ Soc 2006;11:385-400.

[26] Forsyth S. CfE and the Donaldson Report: A coherent approach supporting teachers in the move towards evidence based practice. SATPE Biannual E-Journal - Nov 2014 Edition $2014 ; 1$.

[27] Braun V, Clarke V. Using thematic analysis in psychology. Qual Res Psych 2006;3:77-101.

[28] Clarke V, Braun V. Thematic analysis. J Posit Psychol 2017;12:297-8.

[29] Kitzinger J. Qualitative research. Introducing focus groups. BMJ 1995;311:299-302.

[30] Thomas JR, Silverman S, Nelson J. Research Methods in Physical Activity, 7E: Illinois Human kinetics; 2015.

[31] Huston SA, Hobson EH. Using focus groups to inform pharmacy research. Res Social Ad Pharm 2008;4:186-205.

[32] Mays N, Pope C. Qualitative Research: Rigour and qualitative research. BMJ 1995;311:109-12.

[33] Golafshani N. Understanding reliability and validity in qualitative research. Qual Report 2003;8:597-606. 
[34] Rashotte L. Social influence. The Blackwell encyclopedia of social psychology 2007;9:562-3.

[35] Grenier M, Yeaton P. The Cooperative Learning model as an inclusive pedagogical practice in physical education. Cooperative learning in Physical Education A research-based approach 2012:119-35.

[36] Casey A, Goodyear VA. Can Cooperative Learning Achieve the Four Learning Outcomes of Physical Education? A Review of Literature. Quest 2015;67:56-72.

[37] Green K. Physical education, lifelong participation and 'the couch potato society'1. Phys Educ Sport Pedagogy 2004;9:73-86.

[38] Murdoch E, Whitehead M. Debates in physical education: What should pupils learn in physical education. In: Capel S, Whitehead M, eds. Debates in physical education. London: Routledge; 2012:55-73.

[39] Kirk D. Educational Value and Models-Based Practice in Physical Education. Educational Philosophy and Theory 2013;45:973-86.

[40] Michell L, Amos A. Girls, pecking order and smoking. Soc Sci Med 1997;44:1861-9.

[41] Fraser BP, Brown WJ. Media, Celebrities, and Social Influence: Identification With Elvis Presley. Mass Commun Soc 2002;5:183-206.

[42] Jobanputra J, Clack AR, Cheeseman GJ, Glasier A, Riley SC. A feasibility study of adolescent sex education: medical students as peer educators in Edinburgh schools. BJOG 1999;106:887-91.

[43] Vicsek L. Issues in the analysis of focus groups: Generalisability, quantifiability, treatment of context and quotations. Qual Report 2010;15:122.

[44] Goodyear VA. Outstanding Physical Education Lessons. In: The University of Birmingham- Department of Physical Education, 2016. 


\section{Appendix 1 Topic guide:}

1. Tell me what healthy living means to you?

2. What sort of health issues do think are important to young people like yourself?

3. What sort of things do young people do, that are healthy?

4. What sort of things do young people do, that are unhealthy?

5. What do you understand about PE and health and wellbeing?

6. If you wanted some health advice who would you like to go to?

- Person similar to yourself in age

- Teachers

- Parents

- Health professionals

- other/family

\section{Appendix 2 Phases of Thematic analyses}

Adapted from Braun and Clarke

1. Data familiarisation- Read and re- read the data. Note down general ideas

2. Generate initial codes using a highlighter in the margin of the transcript. Ensure that each piece of data is assigned to the relevant code.

3. Search for themes-Look for a pattern that emerges from the codes. Collate these codes together into relevant themes.

4. Review the themes and codes grouped together

5. Define and name the themes. What does each theme mean? Use an appropriate name for each theme.

6. Write report-Choose relevant detailed extracts. How does this relate to the literature and research aims? 


\section{Appendix 3 Participants Characteristics}

This guide corresponds to the original transcripts and allows the reader an understanding of what school the participant comes from and in what focus group $(F G)$ each particular participant participated in.

\section{School 1}

1-4 FG4

5-8 FG1

9-12 FG2

13-15 FG3

School 2

16-19 FG 5

20-23 FG 6

\section{School 3}

24-27 FG7

28-31 FG8

32-35 FG 9

35-39 FG 10 


\begin{tabular}{|c|c|c|c|}
\hline Respondent & Age & Sex & School year \\
\hline 1 & 13 & $M$ & S2 \\
\hline 2 & 13 & $M$ & S2 \\
\hline 3 & 13 & $\mathrm{M}$ & $\mathrm{S} 2$ \\
\hline 4 & 13 & $\mathrm{M}$ & S2 \\
\hline 5 & 13 & $F$ & S2 \\
\hline 6 & 13 & $\mathrm{~F}$ & S2 \\
\hline 7 & 12 & $\mathrm{~F}$ & S2 \\
\hline 8 & 13 & $F$ & S2 \\
\hline 9 & 12 & $\mathrm{M}$ & S1 \\
\hline 10 & 12 & $\mathrm{M}$ & S1 \\
\hline 11 & 12 & $\mathrm{M}$ & S1 \\
\hline 12 & 12 & $M$ & S1 \\
\hline 13 & 13 & $\mathrm{~F}$ & S2 \\
\hline 14 & 13 & $F$ & S2 \\
\hline 15 & 12 & $\mathrm{M}$ & S2 \\
\hline 16 & 12 & $\bar{M}$ & S1 \\
\hline 17 & 12 & $F$ & $\mathrm{~S} 1$ \\
\hline 18 & 13 & $F$ & S2 \\
\hline 19 & 12 & $\mathrm{~F}$ & S2 \\
\hline 20 & 13 & $M$ & S2 \\
\hline 21 & 13 & $\mathrm{M}$ & S2 \\
\hline 22 & 13 & $\bar{M}$ & S2 \\
\hline 23 & 13 & $\mathrm{M}$ & S2 \\
\hline 24 & 12 & $\mathrm{M}$ & S1 \\
\hline 25 & 12 & $\mathrm{~F}$ & 21 \\
\hline 26 & 12 & $\mathrm{~F}$ & S1 \\
\hline 27 & 12 & $\mathrm{M}$ & S1 \\
\hline 28 & 13 & $\mathrm{M}$ & S2 \\
\hline 29 & 13 & $\mathrm{M}$ & S2 \\
\hline 30 & 13 & $\mathrm{~F}$ & $\mathrm{~S} 2$ \\
\hline 31 & 13 & $\mathrm{M}$ & S2 \\
\hline 32 & 12 & $F$ & S1 \\
\hline 33 & 13 & $F$ & S2 \\
\hline 34 & 12 & $F$ & $\mathrm{~S} 1$ \\
\hline 35 & 12 & $F$ & $\mathrm{~S} 1$ \\
\hline 36 & 12 & $M$ & $\mathrm{~S} 1$ \\
\hline 37 & 13 & $\mathrm{~F}$ & $\mathrm{~S} 2$ \\
\hline 38 & 13 & $\bar{M}$ & S2 \\
\hline 39 & 13 & $\mathrm{M}$ & S2 \\
\hline
\end{tabular}

